\title{
Clinical and Radiographic Examination Compared to Microscopic Examination in the Detection of Anatomical Features of Mesiobuccal Canals in Maxillary First Molars: A Diagnostic Study
}

Comparación entre Examen Radiológico y Clínico con Examen Microscópico en la Detección de Características Anatómicas de los Canales Mesiobucales en los Primeros Molares Maxilares: Un Estudio Diagnóstico

Bispo, B. F. M. ${ }^{1}$ ' Lima, F. J. C. ${ }^{2}$; Oliveira-Neto, O. B. ${ }^{3}$; Monte-Bispo, R. F. ${ }^{2}$; Inojosa, I. F. J. A. ${ }^{4}$; Olave, E. ${ }^{5}$ \& Sousa-Rodrigues, C. F. ${ }^{2}$

BISPO, B. F. M.; LIMA, F. J. C.; OLIVEIRA-NETO, O. B.; MONTE-BISPO, R. F.; INOJOSA, I. F. J. A.; OLAVE, E. \& SOUSARODRIGUES, C. F. Clinical and radiographic examination compared to microscopic examination in the detection of anatomical features of mesiobuccal canals in maxillary first molars: a diagnostic study. Int. J. Morphol., 38(6):1571-1576, 2020.

SUMMARY: The aim of the present study was to determine the accuracy, sensitivity, and specificity of the clinical and radiographic examination (CRE) method compared to the examination with the dental operating microscope (DOM) on the detection of anatomical features of mesiobuccal canals in maxillary first molars. One hundred maxillary first molars were selected to assess the number of canals orifice entrances, accessibility, and ending of their mesiobuccal canals using the CRE method and the examination with the DOM. The diagnostic tests of the CRE exhibited, in general, high levels of accuracy, sensitivity, and specificity. However, low levels of these outcomes occurred, mainly, on the detection of the number of canals entrance orifices of the mesiobuccal root. The statistically significant differences $(\mathrm{p}<0.05)$ occurred for accessibility and ending of canals in 61 of the 62 cases (out of 100) when two of them were present: 2 accessible root canals (48 cases; $77.42 \%$ ), and 1 accessible and 1 inaccessible canals (13 cases; $20.97 \%$ ); 1 foramen after fusion (18 cases; $29.03 \%$ ), 2 foramens (30 cases; $48.39 \%$ ), and 1 foramen and 1 blind foramen (13 cases; $20.97 \%$ ). This study proves that the clinical and radiographic method (still the most commonly used worldwide) can't be trusted absolutely in situations of complex internal anatomy regarding the mesiobuccal root canals of maxillary first molars.

KEY WORDS: Anatomy; Maxilla; First molar; Mesiobuccal canals; Radiology; Dental Operation Microscope.

INTRODUCTION

The maxillary first molar is considered the most treated and less known posterior tooth regarding its internal anatomy, with a high number of endodontic treatment failures. It usually has three roots and three or four root canals. The distobuccal and lingual roots have one canal each, and the mesiobuccal root (MBR) often has two canals mesiobuccal and mesiolingual (MB2) (Pineda, 1973; Vertucci, 1974; De Deus, 1975; Cohen \& Hargreaves, 2011; Weine et al., 2012). The former may be present in $71.1 \%$ of cases (Fogel et al., 1994). However, a MBR with three root canals has been reported, a fact that highlights the complexity of this tooth regarding its internal anatomy (Ferguson et al., 2005).
The MBR of the maxillary first molar has been addressed on in vivo and in vitro studies. These studies aimed to determine the number, frequency, trajectory, and ending of the MB2 canal. The occurrences were higher on in vitro compared to in vivo studies, with differences reaching $38 \%$ favoring the identification of the MB2 canal on in vitro studies (Seidberg et al., 1973; Pomeranz \& Fishelberg, 1974; Sempira \& Hartwell, 2000; de Lima et al., 2014).

Failures on the endodontic treatment of the maxillary first molar are often attributed to the complexity of the internal anatomy of its MBR. The location and proper treatment of the MB2 canal are difficulted by clinical factors,

\footnotetext{
${ }^{1}$ Graduated at the Faculty of Dentistry, Federal University of Alagoas, Maceió - AL, Brazil.

${ }^{2}$ Human Anatomy Division, Institute of Health and Biological Sciences, Federal University of Alagoas, Maceió - AL, Brazil.

${ }^{3} \mathrm{PhD}$ Program, Institute of Health and Biological Sciences, Federal University of Alagoas, Maceió - AL, Brazil.

${ }^{4}$ Endodontics Division, Faculty of Dentistry, Federal University of Alagoas, Maceió - AL, Brazil.

${ }^{5}$ Faculty of Medicine, Universidad de La Frontera, Temuco, Chile.
} 
such as limited access and low visibility, as well as by anatomical factors, such as variability on the number, trajectory, and ending of the MB2 canal (Buhrley et al., 2002).

Recent studies aimed to identify the MB2 canal using new technological resources (Vizzotto et al., 2013; Iino et al., 2014; Mirmohammadi et al., 2015). However, it becomes necessary to verify the diagnostic accuracy of the unaided clinical and radiographic examination (CRE) method, since this method still is the most commonly used worldwide, especially on developing and underdeveloped countries.

Thus, the aim of the present study was to determine the accuracy, sensitivity, and specificity of the clinical and radiographic examination method compared to the examination with the dental operating microscope on the detection of anatomical features of mesiobuccal canals in maxillary first molars.

\section{MATERIAL AND METHOD}

Study design and ethical implications. The present diagnostic study was approved by the Institutional Review Board on Human Studies (Federal University of Alagoas, protocol ID number: 23065.007478/2003-62). Patients read, agreed, and signed the informed consent.

Sample One hundred maxillary first molars were used on the study. Teeth were extracted for surgical reasons and were identified as maxillary first molars according to the criteria described by Dubrul (1991). There were no distinction of age, sex, ethnicity, and soundness of the teeth; however, odontosections at the level of the pulp-chamber floor or teeth with one or more fractured roots were excluded.

After selection, each tooth went through the following preparation process: (1) storage in $10 \%$ formaldehyde during $48 \mathrm{~h}$ and then in $2.5 \%$ sodium hypochlorite during $24 \mathrm{~h}$ to dissolve the organic matter attached to the tooth; (2) washing and brushing on running water to eliminate the sodium hypochlorite; (3) drying and storage in individual plastic bags numerated from one to one hundred; (4) access to the pulp chamber using spherical diamond burs for high speed (Dentsply, Catanduva/SP, Brazil) inclined to lingual seeking the entrance to the lingual canal; (5) compensatory wear of the mesial wall and finishing of the cavity with the Endo Z bur for high speed (Dentsply, Catanduva/SP, Brazil). Thus, a cavity with occlusal divergent walls and triangular shape with base direct to the buccal was obtained (Cohen \& Hargreaves) (Fig. 1); (6) section of the distobuccal and lingual roots at crown level using diamond conical trunk

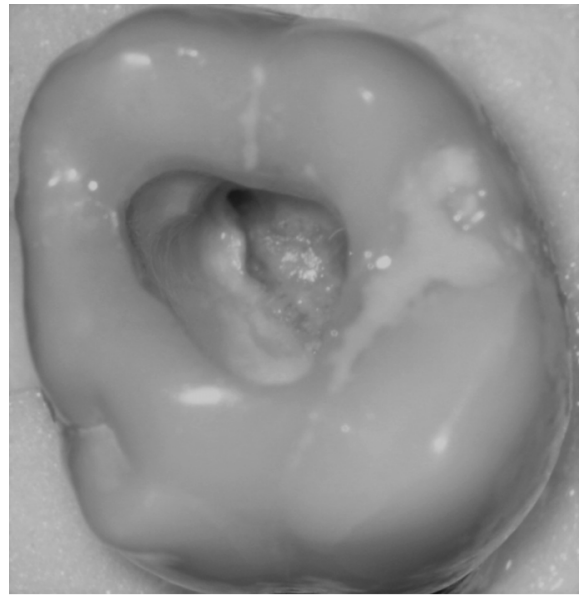

Fig. 1. Access to the pulp-chamber floor and mesiobuccal canals orifice entrances. The cavity has occlusal divergent walls and triangular shape with base direct to the buccal (dental operating microscope, 16x magnification).

burs for high speed (Dentsply, Catanduva/SP, Brazil) to avoid root overlaying during radiographic takes, which would difficult the proper analysis of its canals; (7) pulp chamber irrigation with $1 \%$ sodium hypochlorite solution followed by curettage and aspiration to remove dentin scraping and remaining pulp tissue that could difficult the macroscopic inspection of the root canals.

Clinical and radiographic examination. The number of mesiobuccal canals was clinically determined through visual inspection of the canals entrance orifices on the pulp-chamber floor using an endodontic explorer with posterior insertion of number 06, 08, or $10 \mathrm{~K}$-file (Dentsply, Catanduva/SP, Brazil) to evaluate the accessibility of the canals. The area was well lit by a cold light reflector (Fig. 2).

Using utility wax to fix the mesial surface of the crown and the MBR parallel to the radiographic film, a radiograph was made with distomesial incidence with the $\mathrm{K}$-files previously inserted on the located root canals. All radiographs were made with the same device (Gnatus, Ribeirão Preto/SP, Brazil) with the following parameters fixed: exposure time $(0,8 \mathrm{~s})$, distance to the extremity of the $\mathrm{x}$-ray cone $(6 \mathrm{~cm})$, and kilo-voltage peak $(70 \mathrm{kVp})$. After radiographic take and film processing, the films were analyzed on a negatoscope with the aid of a 2,5 $\mathrm{x}$ magnification loupe to observe the number and ending of the located mesiobuccal canals.

The trajectory of the root canals was determined through radiographic take of the MBR with mesiodistal incidence with the K-files previously inserted in the canals (Fig. 3) and was classified as follows: 


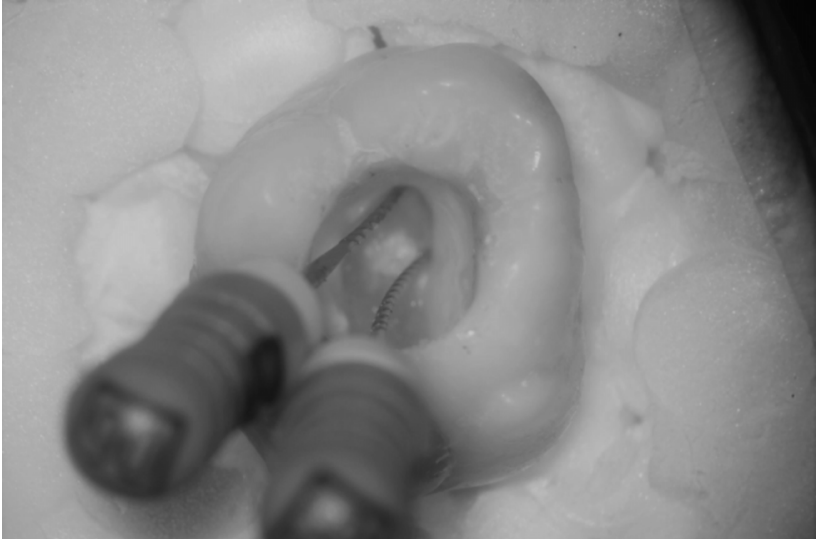

Fig. 2. The number of mesiobuccal canals was clinically determined through visual inspection of the canals orifice entrances on the pulp-chamber floor using an endodontic explorer with posterior insertion of number 06, 08, or $10 \mathrm{~K}$-file (Dentsply, Catanduva/SP, Brazil) to evaluate the accessibility of the canals (dental operating microscope, 16x magnification).

1 canal that ends on 1 apical foramen;

2 canals that end on 2 independent apical foramens;

2 canals that end on 1 apical foramen;

2 canals with one ending on an apical foramen and the other ending on a blind foramen*;

2 canals, both ending on a blind foramen*;

3 canals, with 2 of them ending on a blind foramen*;

3 canals, with 2 of them uniting and ending on a single foramen and the other canal ending on a blind foramen*.

The root canals ending on a blind foramen were determined on the cases that the number $06 \mathrm{~K}$-file did not reach the end of the root.

To evaluate the accessibility of the mesiobuccal canals, number 06, 08, or $10 \mathrm{~K}$-files (Dentsply, Catanduva/ SP, Brazil) were used to locate and explore the root canals. When the file was able to travel through the whole canal it was classified as accessible, otherwise it was classified as inaccessible.

Examination using the dental operating microscope (DOM) as reference standard. The microscopic examination was performed with a dental operating microscope (D.F. Vasconcellos - Valença/RJ, Brazil) with a $16 \mathrm{x}$ magnification. The luminosity was set at the higher level that the DOM could provide. Teeth were examined using and endodontic probe and a number $06 \mathrm{~K}$-file (Dentsply, Catanduva/SP, Brazil) to locate the root canals entrance orifices.

One researcher (BFM) performed the examinations of all teeth. Examinations with the DOM were performed one week after the CRE. BFM was masked to the

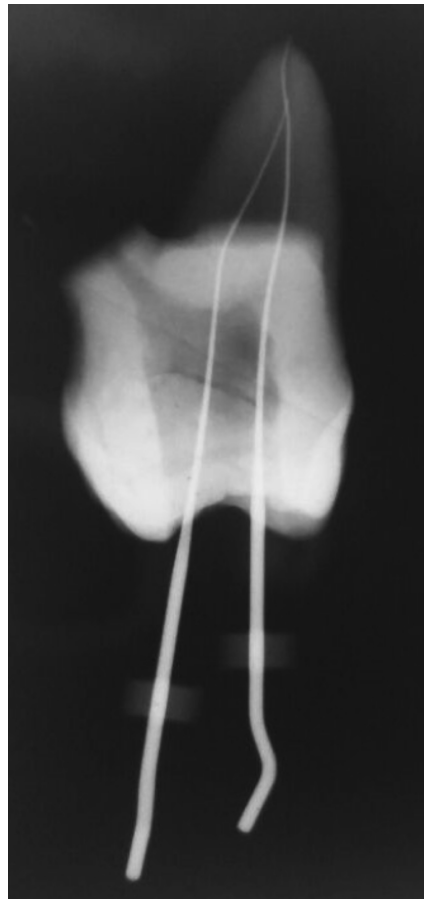

Fig. 3. The trajectory of the root canals was determined through radiographs of the mesiobuccal root with mesiodistal incidence with the $\mathrm{K}$-files previously inserted in the canals.

examination because she always received the teeth from another researcher $(\mathrm{AB})$, which had access to the plastic bags numerated from one to one hundred but did not perform examinations and did not inform BFM which tooth would be examined next.

Statistical analysis. Data were obtained and registered on a Microsoft Excel 2007 sheet using the value "1" to indicate the presence of the outcome and the value " 0 " to indicate the absence of the outcome. The sheet was transported for statistical processing on the IBM SPSS Statistics 20 software, always combining data obtained with the aid of the DOM versus the data obtained from clinical and radiographic resources. The chi-square test was performed to test the null hypothesis and the confidence interval was set at $95 \%$.

The parameters below were calculated using equations for diagnostic tests as follows: Accuracy = $(1 \mathrm{X} 1)+(0 \mathrm{x} 0) /(1 \mathrm{x} 1)+(0 \mathrm{x} 0)+(1 \mathrm{x} 0)+(0 \mathrm{x} 1)$. Concerns the correct diagnostic and is formed by sensitivity and specificity. On the present study accuracy concerned the correct identification of an anatomical feature; Sensitivity $=(1 \mathrm{x} 1) /$ $(1 \times 1)+(1 \times 0)$. Concerns the capability of a diagnostic test to detect the verified positive individuals. In the present study, sensitivity concerned the correct identification of an anatomical feature when it was in fact present; Specificity = $(0 \times 0) /(0 \times 1)+(0 \times 0)$. Concerns the capability of a diagnostic test to detect the truly negative individuals. In the present study, specificity concerned the correct identification of an absent anatomical feature when it was in fact absent. 


\section{RESULTS}

The present study analyzed 100 teeth through clinical examination with and without a dental operating microscope, with the aid of radiographic images, highlighting anatomical features of mesiobuccal canals in maxillary first molars.

Tables I and II show, respectively, results regarding anatomical features found with the CRE and with the aid of the DOM. One can see that major differences occurred for accessibility and ending of canals when two of them were present. Regarding accessibility, the CRE was not able to identify two accessible canals in 11 occasions and one accessible and one inaccessible canal in 7 situations. Regarding the ending of canals, there were 11 cases where the CRE was not able to identify one apical foramen arising from the fusion of two root canals and seven situations that one apical foramen and one blind foramen were present. All aforementioned results were statistically significant $(\mathrm{p}<0.05)$.
Table III shows results of accuracy, sensitivity, and specificity levels regarding the identification of canals entrance orifices, as well as for the assessment of its accessibility and ending using two examination methods.

Considering the means presented on Table III, one can see that the CRE exhibited high levels of accuracy, sensitivity, and specificity. However, in cases where the results differed for the two examination methods, low levels of accuracy [0.39 (IC: 0.34-0.44)], sensitivity [0.08 (IC: 0.050.11 )], and specificity [0.25 (IC: $0.25-0.25$ )] were observed regarding the number of canal entrances. A low level of sensibility [0.33 (IC: 0.28-0.38)] was also found for accessibility of root canals when the CRE did not coincide with the reference standard.

Considering the absolute values presented on Table III, the CRE presented, in general, high levels of accuracy, sensitivity, and specificity. Nevertheless, the CRE showed low levels of accuracy in two cases, of sensibility in seven occasions, and specificity in two situations.

Table I. Anatomical features identified through clinical and radiographic examination (CRE). n: number of teeth diagnosticated with a certain anatomical feature.

\begin{tabular}{|c|c|c|c|c|c|}
\hline \multicolumn{2}{|c|}{$\begin{array}{c}\text { Canals orifice entrances - } \\
\text { CRE }\end{array}$} & \multicolumn{2}{|c|}{ Canals - CRE } & \multicolumn{2}{|c|}{ Foramens - CRE } \\
\hline Description & $\mathrm{n}$ & Description & $\mathrm{n}$ & Description & $\mathrm{N}$ \\
\hline One & $36^{*}$ & 1 acces sible & $36(100 \%)^{*}$ & 1 foramen & $36(100 \%)^{*}$ \\
\hline \multirow[t]{5}{*}{ Two } & $62 *$ & 2 acces sible & $48(77,42 \%)^{*}$ & 1 foramen after fusion & $18(29,03 \%)^{*}$ \\
\hline & & & & 2 foramens & $30(48,39 \%)^{*}$ \\
\hline & & 1 accessible and & $13(20,97 \%)^{*}$ & 1 foramen and 1 blind foramen & $13(20,97 \%)^{*}$ \\
\hline & & 1 inaccessible & & & \\
\hline & & 2 inaccessible & $01(1,61 \%)$ & 2 blind foramens & $01(1,61 \%)$ \\
\hline \multirow[t]{3}{*}{ Three } & $02 *$ & $\begin{array}{l}2 \text { accessible and } \\
1 \text { inaccessible }\end{array}$ & $01(50 \%)^{*}$ & $\begin{array}{l}1 \text { foramen after fusion and } 1 \\
\text { blind foramen }\end{array}$ & $01(50 \%)^{*}$ \\
\hline & & 1 accessible and & $01(50 \%)^{*}$ & 1 foramen and 2 blind & $01(50 \%)^{*}$ \\
\hline & & 2 inacces sible & & foramens & \\
\hline
\end{tabular}

* $\mathrm{p}<0,05$ using the chi-square test.

Table II. Anatomical features identified through the examination with the dental operating microscope (DOM). n: number of teeth diagnosticated with a certain anatomical feature.

\begin{tabular}{|c|c|c|c|c|c|}
\hline \multicolumn{2}{|c|}{$\begin{array}{c}\text { Canals orifice entrances - } \\
\text { DOM }\end{array}$} & \multicolumn{2}{|c|}{ Canals - DOM } & \multicolumn{2}{|c|}{ Foramens - DOM } \\
\hline Description & $\mathrm{n}$ & Description & $\mathrm{n}$ & Description & $\mathrm{N}$ \\
\hline \multirow[t]{4}{*}{ Two } & $80 *$ & 2 accessible & $59(73,75 \%)^{*}$ & 1 foramen after fusion & $29(36,25 \%)^{*}$ \\
\hline & & & & 2 foramens & $30(37,5 \%)^{*}$ \\
\hline & & 1 accessible and & $20(25 \%)^{*}$ & 1 foramen and 1 blind & $20(25 \%)^{*}$ \\
\hline & & 2 inaccessible & $01(1,25 \%)$ & 2 blind foramens & $01(1,25 \%)$ \\
\hline \multirow[t]{4}{*}{ Three } & $02 *$ & 2 accessible and & $01(50 \%)^{*}$ & 1 foramen after fusion and & $01(50 \%)^{*}$ \\
\hline & & 1 inaccessible & & 1 blind foramen & \\
\hline & & 1 accessible and & $01(50 \%)^{*}$ & 1 foramen and 2 blind & $01(50 \%)^{*}$ \\
\hline & & 2 inaccessible & & foramens & \\
\hline
\end{tabular}

*p $<0,05$ using the chi-square test. 
Table III. Diagnostic tests of the clinical and radiographic examination compared to the examination with the dental operating microscope.

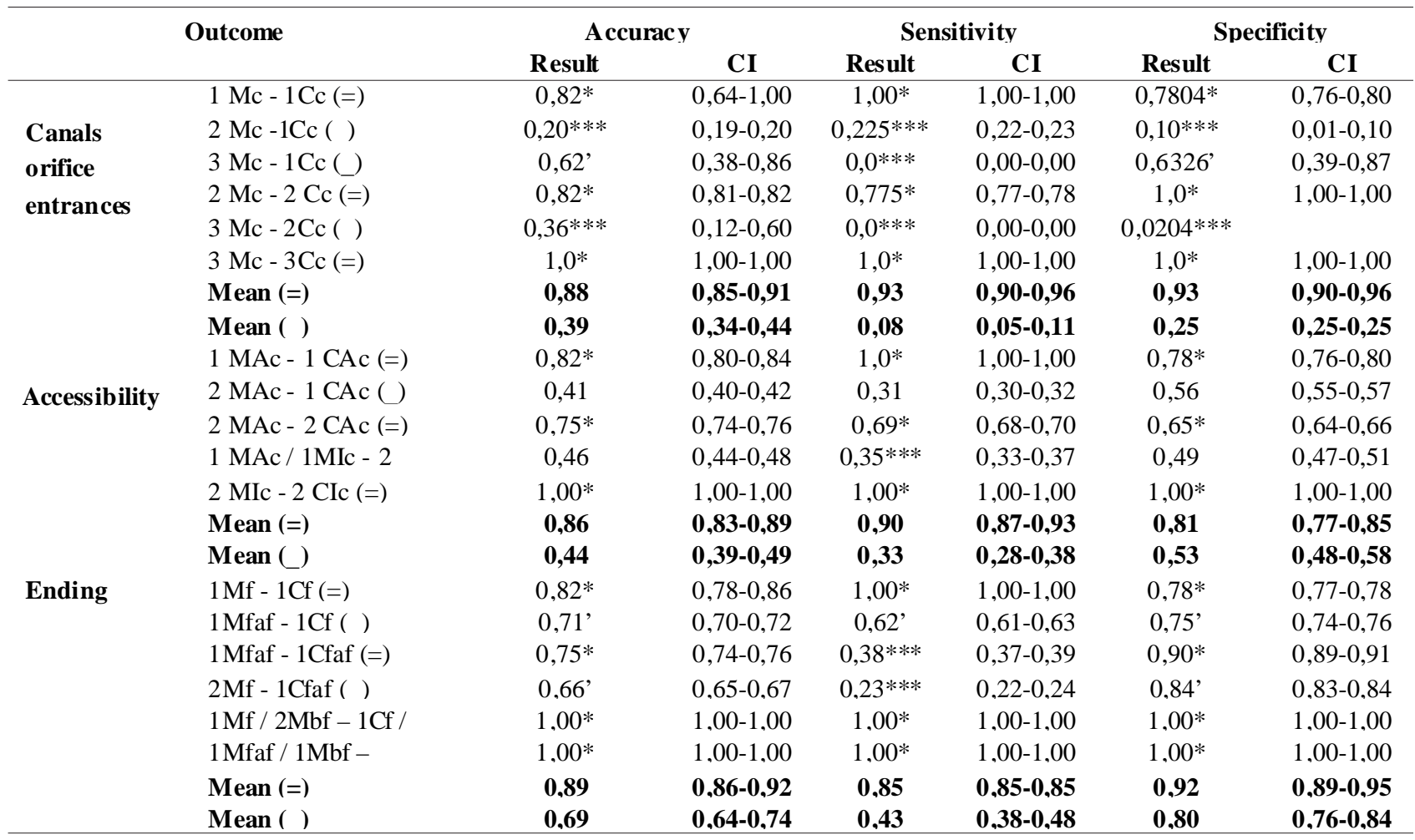

CI: confidence interval; Mc: canals identified with the microscope; Cc: canals identified clinically; MAc: accessible canals found with the microscope; CAc: accessible canals found clinically; MIc: inaccessible canals found with the microscope; CIc: inaccessible canals found clinically; Mf: foramen found with the microscope; Cf: foramen found clinically; Mfaf: foramen after fusion found with the microscope; Cfaf: foramen after fusion found clinically; (=) when the outcomes were equal between the clinical and radiographic examination and the examination with the dental operating microscope; (?) when the outcomes were dif ferent between the clinical and radiographic examination and the examination with the dental operating microscope; $*=$ indicates a high level of the outcome with the signal (=); $* *=$ indicates a moderate level of the outcome with the signal $(=) ; * * *=$ indicates a low level of the outcome; ' $=$ indicates a low level of the outcome with the signal (?).

\section{DISCUSSION}

The diagnostic accuracy of the CRE was compared to accuracy of the examination aided with the DOM. Other diagnostic studies were performed; nevertheless, these studies compared the accuracy of technological resources such as cone beam computed tomography and optical coherence tomography with microcomputed tomography (BaldassariCruz et al., 2002; Vizzotto et al.; Iino et al.; Mirmohammadi et al.). Despite technological breakthroughs may help clinicians to detect and to properly treat root canals of complex anatomy, the CRE method still is the most commonly used method in endodontic treatment, especially in developed and underdeveloped countries.

Regarding anatomical features of mesiobuccal canals in maxillary first molars analyzed in the present study, major differences occurred for accessibility and ending of root canals when two of these were present, totaling 36 occasions (36\%) in which the CRE was not able to detect the correct number of canals (either accessible or not), as well as their apical endings
(Tables I and II). Clinicians must be aware of these occurrences since an incorrect anatomical diagnosis, especially concerning the accessibility of root canals, is a key factor for endodontic treatment failure, because one or more canals will not be located and, therefore, will not be properly treated.

There were 23 cases in which the examination with the DOM detected the presence of one or more canals with a blind foramen (Table II). In seven of these occasions (30.43 $\%$ ), the CRE was not able to detect that the canals ended on one apical foramen and one blind foramen. It is important to highlight, however, that a blind foramen may not be the ending of the canal when the canal is an intercanal (Pucci \& Reig, 1944). This morphology is unfeasible for a proper endodontic treatment.

The diagnostic tests of the CRE exhibited, in general, high levels of accuracy, sensitivity, and specificity. However, one must consider the cases in which the CRE exhibited low levels of these outcomes (Table III). This occurred, mainly, in the detection of the number of canals entrance orifices of the MBR. These data indicate a considerable possibility of 
failures on the traditional clinical examination to locate a second or even a third entrance orifice in the aforementioned root, which may be a decisive factor for endodontic treatment failure (Ferguson et al.).

Only one study used diagnostic tests to compare the DOM examination with the unaided visual inspection and the swept-source optical coherence tomography on the detection of the MB2 canal in maxillary molars (Iino et al.). As for the comparison of the DOM with the visual examination, the authors found accuracy, sensitivity, and specificity values that were similar to the results found in our study (Table III). Nevertheless, it is important to highlight that our study differs from the previously mentioned paper, because we not only analyzed the presence and number of root canals but we also examined the accessibility and the ending of the canals. Therefore, to the best of our knowledge, our study is the first to address these outcomes using diagnostic tests to compare the clinical examination with the DOM examination.

The CRE presented high levels of the diagnostic outcomes compared to the DOM examination. However, clinicians must be aware of the cases, in that the two examination methods exhibited considerable discrepancy. This occurred, mainly, when two or three canals entrance orifices were located on the MBR.

BISPO, B. F. M.; LIMA, F. J. C.; OLIVEIRA-NETO, O. B.; MONTEBISPO, R. F.; INOJOSA, I. F. J. A.; OLAVE, E. \& SOUSARODRIGUES, C. F. Comparación entre examen radiológico y clínico con examen microscópico en la detección de características anatómicas de los canales mesiobucales en los primeros molares maxilares: un estudio diagnóstico. Int. J. Morphol., 38(6):1571-1576, 2020.

RESUMEN: El objetivo del presente estudio fue determinar la precisión, sensibilidad y especificidad del método de examen clínico y radiográfico (ECR) en comparación al examen con el microscopio quirúrgico dental (MQD) en la detección de características anatómicas de los canales mesiovestibulares en primeros molares maxilares.Se seleccionaron 100 primeros molares maxilares para evaluar el número de entradas de los canales, la accesibilidad y la terminación de sus canales mesiovestibulares utilizando el método ECR y el examen con el MQD.Las pruebas de diagnóstico del ECR exhibieron, en general, altos niveles de precisión, sensibilidad y especificidad. Sin embargo, también hubo niveles bajos de estos resultados, principalmente, en la detección del número de orificios de entrada a los canales de las raíces mesiovestibulares. Hubo diferencias estadísticamente significativas $(\mathrm{p}<0,05)$ para la accesibilidad y terminación de los canales en 61 de los 62 casos (del total de 100), cuando dos de ellos estaban presentes: 2 canales radiculares accesibles ( 48 casos, 77,42\%), y 1 accesible y 1 inaccesible (13 casos, 20,97\%). Después de la fusión, un orificio (18 casos, $29,03 \%$ ), 2 orificios ( 30 casos, $48,39 \%$ ) y 1 orificio más otro, ciego (13 casos, $20,97 \%$ ). Este estudio demuestra que no se puede confiar plenamente en el método clínico y radiográfico (todavía el más utilizado en todo el mundo), cuando existe una anatomía interna compleja de los canales de la raíz mesiovestibular de los primeros molares superiores.

PALABRAS CLAVE: Anatomía; Maxilar; primer molar; Canales mesiobucales; Radiología; Microscopia quirúrgica dental.

\section{REFERENCES}

Baldassari-Cruz, L. A.; Lilly, J. P. \& Rivera, E. M. The influence of dental operating microscope in locating the mesiolingual canal orifice. Oral Surg. Oral Med. Oral Pathol. Oral Radiol. Endod., 93(2):190-4, 2002.

Buhrley, L. J.; Barrows, M. J.; BeGole, E. A. \& Wenckus, C. S. Effect of magnification on locating the MB2 canal in maxillary molars. J. Endod., 28(4):324-7, 2002

Cohen, S. \& Hargreaves, K. M. Pathways of the Pulp. Rio de Janeiro, Elsevier, 2011. pp. 180

De Deus, Q. D. Frequency, location, and direction of the lateral, secondary, and accessory canals. J. Endod., 1(11):361-6, 1975.

de Lima, F. J. C.; Montagner, F.; Jacinto, R. C.; Ambrosano, G. M. B. \& Gomes, B. P. F. A. An in vitro assessment of type, position and incidence of isthmus in human permanent molars. J. Appl. Oral Sci., 22(4):274-81, 2014.

Dubrul, E. L. Anatomia Oral de Sicher e Dubrul. Porto Alegre, Artes Médicas, 1991. pp.390

Ferguson, D. B.; Kjar, K. S. \& Hartwell, G. R. Three canals in the mesiobuccal root of a maxillary first molar: a case report. J. Endod., 31(5):400-2, 2005.

Fogel, H. M.; Peikoff, M. D. \& Christie, W. H. Canal configuration in the mesiobuccal root of the maxillary first molar: a clinical study. J. Endod., 20(3):135-7, 1994.

Iino, Y.; Ebihara, A.; Yoshioka, T.; Kawamura, J.; Watanabe, S.; Hanada, T.; Nakano, K.; Sumi, Y. \& Suda, H. Detection of a second mesiobuccal canal in maxillary molars by swept-source optical coherence tomography. J. Endod., 40(11):18658,2014 .

Mirmohammadi, H.; Mahdi, L.; Partovi, P.; Khademi, A.; Shemesh, H. \& Hassan, B. Accuracy of cone-beam computed tomography in the detection of a second mesiobuccal root canal in endodontically treated teeth: an ex vivo study. $J$. Endod., 41(10):1678-81, 2015.

Pineda, F. Roentgenographic investigation of the mesiobuccal root of the maxillary first molar. Oral Surg. Oral Med. Oral Pathol., 36(2):253-60, 1973.

Pomeranz, H. H. \& Fishelberg, G. The secondary mesiobuccal canal of maxillary molars. J. Am. Dent. Assoc., 88(1):119-24, 1974.

Pucci, F. M. \& Reig, R. Conductos Radiculares: Anatomía, Patología y Terapia. Montevideo, Casa A. Barreiro y Ramos, 1944. pp.490.

Seidberg, B. H.; Altman, M.; Guttuso, J. \& Suson, M. Frequency of two mesiobuccal root canals in maxillary permanent first molars. J. Am. Dent. Assoc., 87(4):852 $6,1973$.

Sempira, H. N. \& Hartwell, G. R. Frequency of second mesiobuccal canals in maxillary molars as determined by use of an operating microscope: a clinical study. J. Endod., 26(11):673-4, 2000.

Vertucci, F. J. The endodontic significance of the mesiobuccal root of the maxillary first molar. U. S. Navy Med., 63(5):29-31, 1974

Vizzotto, M. B.; Silveira, P. F.; Arús, N. A.; Montagner, F.; Gomes, B. P. F. A. \& Silveira, H.E.D. CBCT for the assessment of second mesiobuccal (MB2) canals in maxillary molar teeth: effect of voxel size and presence of root filling. Int. Endod. J., 46(9):870-6, 2013.

Weine, F. S.; Healey, H. J.; Gerstein, H. \& Evanson, L. Canal configuration in the mesiobuccal root of the maxillary first molar and its endodontic significance. 1969. J. Endod., 38(10):1305-8, 2012.

Corresponding author:

Prof. Dr. Rodrigo Freitas Monte Bispo

Human Anatomy Division

Institute of Health and Biological Sciences

Federal University of Alagoas

Maceió - AL - BRAZIL

Email: rodrigo_rfmb@yahoo.com.br

Received: 10-05-2020

Accepted: 22-06-2020 